\title{
The utility of mosquito-borne disease as an environmental monitoring tool in tropical ecosystems
}

\author{
Andrew Jardine, ${ }^{* a}$ Angus Cook $^{a}$ and Philip Weinstein ${ }^{a}$
}

The intrinsic link between ecosystem health and human health has been firmly established in the literature and has given rise to the development of new multidisciplinary fields of research such as medical geology. An important practical implication of the ecosystem health approach is the utility of human disease outbreaks as indicators of underlying ecosystem disruption. The use of such a bioindicator is particularly relevant in developing countries where monitoring of traditional environmental and ecological indicators is not routinely undertaken. Mosquito-borne diseases appear to have the most potential as bioindicators in tropical regions because the burden of disease is high, the disease ecology has a strong environmental component and intensive surveillance systems are well established. Evidence is reviewed regarding the utility of mosquito-borne disease to detect a range of ecosystem insults including: hydro-geological disruption in soil-water systems (e.g. secondary soil salinisation and waterlogging); escalating agricultural intensification;

deforestation; and urbanisation. The evidence suggests that overall, mosquito-borne disease is a specific but insensitive indicator, because human modification of natural ecosystems does not always result in increases in disease incidence and can, in some cases, lead to reductions.

Nevertheless, mosquito-borne disease remain useful as bioindicators if utilised as a complement to traditional environmental variables in identifying ecological disturbances; they can then assist in directing interventions that are concurrently beneficial to both human health and ecosystem health.

\section{Introduction}

The Millennium Ecosystem Assessment (MEA) has conducted the first major integrated global assessment examining degradation of ecosystems and the impact this process has on the health of humans which inhabit them ${ }^{1}$. It highlights that physical, chemical and biological anthropogenic influences such as restructuring (e.g. land use change, deforestation, water resource development), over harvesting, introduction of exotic species, and contamination of air, land or water, all contribute to disruption of natural ecosystems. Such disruptions can impact human health directly (e.g. flood, fire) or indirectly (e.g. livelihood loss and, most importantly in the context of this paper, increases in disease transmission due to changes in the ecology of disease vectors). The rate of ecosystem change has accelerated rapidly over the last 50 years due to increased utilisation of ecosystem services and human intervention, putting pressure on existing ecosystem services. Although many changes may improve health locally in the short term, detrimental effects may be displaced in time and/or space. ${ }^{1}$ As has previously been summarised in simple terms, the key message of the MEA report is that "ecosystem degradation has happened, it is bad for us, and it is going to get worse unless we intervene radically". 2

Research into human health issues using an ecosystem approach must inherently be multidisciplinary to take into account the range of systems and processes involved. ${ }^{3,4}$ New fields of research have been developed to meet this need, an excellent example being medical geology.,

\footnotetext{
${ }^{a}$ School of Population Health, The University of Western Australia, 35 Stirling Highway, Crawley, Western Australia, 6009. Fax: +618 6488 1188; Tel: +618 6488 1296; E-mail: u4052357@anu.edu.au
}

Medical geology is defined as the study of the relationship between the geosphere and human health, and focuses on current issues that generally involve exposure to toxic elements or compounds of direct geogenic origin (such as mercury and asbestos), but including geosphere modifications which may indirectly affect human health (groundwater mismanagement) ${ }^{7}$. As such it is by definition dependent on multidisciplinary research collaborations involving at least geologists and health professionals, but more often also climatologists, ecologists, anthropologists, and others. The monitoring needs of these research teams are therefore also multidisciplinary, with environmental monitoring and health outcome data both being essential. ${ }^{8}$ In this paper, we explore examples of the interplay between such monitoring data using tropical mosquito borne diseases and their relationship to changes at the soil-water interface, including secondary soil salinisation, waterlogging, agriculture, forestry, and urbanisation.

The holistic ecosystem health approach places equal emphasis on the dual endpoints of human and ecosystem health, and recognises that both must be taken into consideration for sustainable development to occur. ${ }^{9}$ The recognition of these dual endpoints generates several important practical implications for the rapidly growing populations in tropical regions. ${ }^{10}$ Human health can be used as a 'yardstick' of the health of the ecosystems in which these communities are located. ${ }^{11}$ Thus human health data, which are generally more closely monitored than ecological indicators, can be used to direct rapid and appropriate ecosystem interventions to improve the health of the environment, which will ultimately manifest as an improved health status for the resident human population. ${ }^{12}$

A major advantage in using disease outbreaks as bioindicators of even subtle ecosystem disruptions is that 
the health of human populations is generally subject to more widespread and more accurate surveillance than is ecosystem health. ${ }^{12}$ Nowhere is this more relevant than in non-industrialised nations, where the infrastructure and resources to monitor disruptions to the hydro-geosphere are generally not available. In contrast, many sources of data such as those obtained from communicable disease notification systems - provide ongoing measurement and monitoring of human communities in even the most challenging socio-economic environments. Traditional environmental bioindicators (such as water quality, biodiversity or changes in nutrient cycling) and more recent advanced indices (such as thermodynamics, resilience estimates, exergy, and emergy) are indisputably accurate indicators of ecosystem disruption, but are much more complex and difficult to collect and require an expensive and dedicated research effort, often over many months or years. ${ }^{13}$ The collection of such data is likely to be a lower priority for the limited health expenditure in developing countries than human infectious disease data collection.

One of the most pertinent sources of health data that can be used to signal underlying ecosystem processes relates to environmentally mediated vector-borne diseases. The MEA has prioritised a number of vector-borne diseases based on global burden of disease data and sensitivity to ecological change, including: ${ }^{14}$

- malaria across most ecological systems;

- lymphatic filariasis and Japanese encephalitis virus in cultivated and inland water systems in the tropics;

- $\quad$ dengue in tropical urban centres;

- West Nile Virus in urban and suburban systems of Europe and North America.

Clearly the diseases of most relevance in nonindustrialised countries, particularly in tropical biomes, that also appear to be the most inherently suitable for evaluating ecosystem change, are those borne by mosquitoes. The purpose of this paper is to consider interactions at the soil water interface that affect mosquito-borne disease incidence, and to discuss the utility of mosquito-borne disease in tropical ecosystems as a proxy to both detect underlying ecosystem disruption and to direct rapid and appropriate interventions.

\section{The re-emergence of mosquito-borne disease}

Mosquito-borne diseases are re-emerging as a significant threat to public health worldwide. ${ }^{15}$ Despite persistent control and eradication efforts throughout the $20^{\text {th }}$ century, malaria remains the most prevalent infectious disease affecting humans worldwide. In fact, global morbidity and mortality due to malaria has increased in recent decades with resistance developing to antimalarial drugs, the spread of disease to new areas and re-emergence in regions where malaria was previously thought to have been eliminated ${ }^{16}$. There has also been a significant increase in activity of several important existing arboviral diseases over recent decades. ${ }^{17}$ As with malaria, arboviral epidemics have occurred in areas thought to be effectively under control and many viruses have expanded into new geographic areas. ${ }^{18,19}$ The resurgence of dengue/dengue haemorrhagic fever and yellow fever, two examples of the re-emergence of arboviruses previously thought to be under control, have been reviewed by Gubler. ${ }^{20}$ Arboviral expansion into new geographic areas is clearly illustrated by the incursion and establishment of West Nile virus (WNV) into the United States $^{21,22}$ and the recent rapid emergence of Chikungunya in the Indian Ocean region. ${ }^{23-25}$

\section{Mosquito-borne disease as an indicator of disrupted soil/water systems}

As we head into the 21st century it is predicted that water availability will be one of the key factors that will limit development. Between 1900 and 1995, water withdrawal worldwide increased six-fold, more than twice the rate of population growth. ${ }^{26}$ It is also estimated that climate change will account for approximately $20 \%$ of the increase in global water scarcity over the next 20 years and many tropical and subtropical regions in particular are likely to receive lower and more erratic rainfall. ${ }^{27}$ Thus we will become more reliant on modifying water systems to ensure continued supply.

The artificial provision of water comes at a cost in terms of increasing the potential for mosquito breeding and associated disease transmission. Water resource developments such as dam construction, establishment of artificial wetlands, and agricultural irrigation are important examples of such changes that may support mosquito breeding and influence associated disease transmission. Over 45,000 'large' dams greater than $15 \mathrm{~m}$ high and countless more small dams currently exist worldwide, predominantly in the Asian region, and new large dams are being constructed at a rate of 160 to 320 per year. In many cases economic, rather than environmental or ecological considerations, have taken precedence when considering the long-term impact of dam construction. ${ }^{28}$ Altered flow regimes downstream and increased water volume upstream have important ecological implications, including changes in mosquito breeding and associated disease transmission. ${ }^{29}$ 30. The construction of artificial wetlands for a range of purposes, such as effluent treatment or filtering of urban storm water runoff prior to entering rivers, has also been associated with mosquito breeding. ${ }^{31}$

Disruptions to hydrogeology can influence mosquito breeding and alter associated disease risk by means of secondary soil salinisation and waterlogging. Based on a review of salinity tolerance studies on various mosquito species, Mulla et al. ${ }^{32}$ conclude that soil and water salinisation may result in a composition change or succession of mosquito species and thus influence associated disease risks. Soil salinisation can lead to changes in the abundance and distribution of vector mosquitoes either (1) directly, as the waterlogged soil provides a greater area and temporal duration of potential mosquito breeding habitat following rainfall; and/or (2) indirectly, through a decrease in biodiversity of aquatic invertebrate predators that may be more salt sensitive 
leading to a reduction in interspecific resource competition. $^{33}$

Waterlogging and soil salinisation are mentioned as potential environmental risk factors for malaria in Egypt ${ }^{34}$ and Saudi Arabia, ${ }^{35}$ although the association is not tested. Temel $^{36}$ used correlation, regression and spatial analysis to examine the agricultural, environmental, and institutional determinants of malaria in Azerbaijan in 1999. Soil salinity was both positively correlated (correlation coefficient 0.34 ) and significantly related in the regression analysis to increasing malaria incidence. Spatial analysis using geographical information systems (GIS) also showed that malaria incidence was highest in low lying, saline regions. However no statistical spatial analysis was undertaken to formally test this association and no entomological investigations of mosquito species present were undertaken as part of the study.

A converse temporal association is apparent in Punjab, Pakistan where secondary soil salinisation increased over recent decades but malaria incidence decreased. Klinkenberg et al. $^{37}$ compared routinely collected entomological surveillance records with historical ground water levels and conductivity data in the Bahawalnagar district in southern Punjab from 1970 to 1999. They showed that as salinity increased, species composition changed significantly over the study period $(\mathrm{p}<0.001)$ from a predominance of An. culicifaces to An. stephensi. General linear modelling showed a change in the abundance of $A n$. stephensi relative to An. culicifacies of approximately 2\% per year over the study period, until by 1999 the percentage of rooms surveyed positive for An. stephensi and An. culicifaces was approximately $50 \%$ and $20 \%$ respectively. Although both species are known vectors of malaria in rural Pakistan, An. culicifacies is considered to be the primary vector - and is also less salt tolerant than An. stephensi. ${ }^{37}$

These two studies demonstrate the potential for mosquito borne disease risk to be altered as a result of soil salinisation. In the latter case the more salt tolerant mosquito species was a less efficient disease vector: however when the reverse is true, such as in south-west Western Australia where the development of dryland salinity appears to have favoured the inland spread of the Ross River virus vector Aedes camptorhynchus, ${ }^{38}$ the hypothesis would predict an increased risk to human health.

\section{Mosquito-borne disease as an indicator of escalating agricultural intensification}

Agriculture is the key driver of water resource development, accounting for approximately $40 \%$ of global land area ${ }^{39}$ and $85 \%$ of consumptive water use. ${ }^{40}$ Agriculture is also independently highly ecologically disruptive because it involves clearing of biodiverse native vegetation and replacement by monoculture crops. Thus simplified, nutrient rich ecosystems are deliberately maintained, in which crop genetics, soil fertility and pests are all tightly controlled. ${ }^{41}$ Agriculture is driven primarily by production of commodities of economic value, and therefore ecological values are largely forgotten. ${ }^{42}$ If current trends continue, the global area under agricultural management will double by 2050, driving further habitat destruction, eutrophication and loss of ecosystem services. ${ }^{43}$

Escalating agricultural development may directly impact on human health through increasing pollution, pesticide use, non-medical use of antibiotics and emerging zoonotic diseases (e.g. bovine spongiform encephalopathy). ${ }^{44}$ However the indirect human health risks resulting from such large scale agricultural development are potentially even more significant. $^{45}$

Agricultural irrigation development reduces ecological diversity and may favour colonisation of new plants and animals, including pest species. ${ }^{46}$ The presence of water is integral to the survival, growth and development of both agricultural crop plants and mosquito larvae. Thus irrigation for agricultural purposes that is not carefully managed and produces standing water long enough for larvae to fully develop provides ideal mosquito breeding habitat. Surface/furrow irrigation associated with rice fields, irrigated crops and pastures is highly conducive to breeding of many disease carrying mosquito species. ${ }^{32}$

Studies in tropical areas have shown that the mosquito breeding season may be extended in areas with controlled irrigated agriculture, with peaks in mosquito abundance during the dry season coinciding with water releases into irrigation canals and fields. ${ }^{47-49}$ Recent studies in Mali ${ }^{50,51}$ and the northern tropics of Western Australia ${ }^{52}$ have shown that irrigated areas can sustain continuous, year round mosquito breeding that would not be otherwise be possible in non-irrigated areas due to lack of rainfall in dry season months.

Extensive irrigation schemes required for rice cultivation have been associated with breeding of mosquito vectors for a range of diseases including Japanese encephalitis, lymphatic filariasis, West Nile and Rift Valley fevers, and most frequently, malaria. ${ }^{53}$ Agricultural development and associated environmental changes have played a pivotal role in the natural history and spread of malaria. ${ }^{54}$ The relationship between irrigation development for rice cultivation, breeding of Anopheles mosquitoes and malaria transmission in local communities has been documented in the literature as far back as $1882^{55}$ cited in 56 and the term 'rice malaria' was coined in the 1930's to describe this well recognised association. ${ }^{46}$ Evidence from tropical regions has consistently shown an association between irrigation, particularly for rice cultivation, and breeding of malaria vectors. $^{\text {57-61 }}$

However, the complex nature of mosquito-borne disease transmission means that the exact impact on health is often variable and difficult to predict. Indeed, a recent review of the impact of sixty examples of land use change on anopheline ecology found that in 36 examples anopheline density increased, resulting in an increase in local malaria transmission in 25 of these cases and, no significant change in the other 11. Anopheline density decreased in the remaining 24 examples, of which a decrease in malaria transmission was observed in only 8 cases. ${ }^{62}$ A number of field studies in Africa have shown that although rice cultivation was associated with increased mosquito 
breeding, this translated into a greater prevalence of malaria only in areas of fringe transmission where immunity was low. ${ }^{63}$ In fact, in areas with stable malaria transmission, the introduction of rice irrigation schemes generally decreased the incidence of malaria due to a higher standard of living in irrigated areas relative to non-irrigated areas, resulting in increased use of anti-malarial drugs and other protective measures. ${ }^{63,64}$ This relationship is further confounded by a range of social and cultural changes that occur following the introduction of rice cultivation. ${ }^{65}$ Therefore it appears that while the potential for higher transmission is increased by rice cultivation, the complex ecology of malaria means that the impact on disease transmission is not always consistent. The implications of this are discussed later.

\section{Mosquito-borne disease as an indicator of deforestation}

Another important driver of ecosystem change in tropical regions is deforestation. Current estimates indicate that approximately 5.8 million hectares of humid tropical forest is cleared each year with a further 2.3 million hectares significantly degraded and fragmented. ${ }^{66}$

The implications of deforestation for malaria in Africa have long been recognised. ${ }^{67}$ Forests do not provide a favourable breeding habitat for the primary vector, An. gambiae, because this species prefers open sunlit habitats and the forest floor tends to absorb standing water. "It is only when man cuts down the forest that breeding places for An. gambiae become almost infinite". ${ }^{67}$ This observation has been confirmed by empirical research that demonstrates, at a local level, both a direct link between deforestation and malaria transmission potential, ${ }^{68,69}$ and also an indirect link through modification of the local microclimate $\mathrm{e}^{70,71}$.

Similar findings have been observed in the Amazonian region $^{72}$ where malaria transmission is closely linked to anthropogenic processes, particularly landscape change. ${ }^{73} \mathrm{~A}$ recent study in the Peruvian Amazon reported a human biting rate of the major local malaria vector, An. darlingi, that was more than 278 times higher in deforested compared to predominantly forested areas. ${ }^{74}$ Deforestation has also been linked to enhanced transmission of several arboviral diseases in the Brazilian Amazon. ${ }^{75}$

\section{Mosquito-borne disease as an indicator of urbanisation}

Urbanisation results in greatly increased human population densities and significant environmental modification. Well planned urbanisation development with appropriate sanitation facilities and infrastructure is not generally associated with increased mosquito borne disease risk. However even in modern Western urban areas, subterranean storm water and sewerage systems can harbour mosquitoes and facilitate disease transmission. ${ }^{76-79}$

Dengue fever is a major health risk in tropical urban areas because the main vector, Ae. aegypti, is highly adapted to, and strongly associated with, high density urban environments. ${ }^{80}$ It breeds in artificial containers such as pots, vases, tanks and discarded tyres, and has a strong preference for feeding on humans. Transmission cycles occur directly between mosquitoes and humans and do not involve an animal reservoir. ${ }^{81}$ The re-emergence of this disease as a global health issue has been linked with rapid, unplanned urbanisation in developing tropical regions over the latter part of the $20^{\text {th }}$ century ${ }^{82}$ and strongly correlated with rapid human population expansion. ${ }^{83}$

However in the case of malaria in tropical regions, urbanisation generally tends to limit the availability of breeding habitat and reduce transmission. A meta-analysis of studies from tropical sub-Saharan Africa demonstrated a general negative linear relationship between urbanicity and annual entomological inoculation rates (the number of bites of infected mosquitoes received per person per year) with mean annual rates of 7.1 in urban centers, 45.8 in peri-urban areas, and 167.7 in rural areas. ${ }^{84}$ Significant variation was observed both between and within cities, caused by differential patterns of landuse, human demographics, municipal initiatives, and individual and household variables. Similarly, on the Indian Ocean island Réunion, rapid urbanisation appears to have been instrumental in the successful eradication of malaria: The small $\left(2500 \mathrm{~km}^{2}\right)$ island, which is part of France, experienced rapid urbanisation in the second half of the 20th century (currently 750,000 inhabitants), and although the malaria eradication campaign carried out there in the 1950s was no different from those elsewhere, ${ }^{85}$ unlike most tropical locations Réunion has managed to maintain its malaria free status without further intervention. ${ }^{86}$ However unplanned urban development without proper consideration for sanitation and water disposal can still lead to increased malaria transmission as demonstrated in the Brazilian city of Manaus-Amazonas. ${ }^{87}$

\section{Conclusions}

The increasing move toward merging existing fields of research and development of new integrated fields such as medical geology has generated new approaches to intervention for existing environmental and public health problems. As we have suggested previously, one such novel approach is the use of human disease outbreaks to rapidly identify underlying ecosystem disruption at a range of levels, and guide prompt and appropriate interventions that are beneficial to both human and ecosystem health. ${ }^{12}$

The high burden of many mosquito-borne diseases, sensitivity to environmental change and the existence of more comprehensive disease surveillance systems in tropical regions compared to traditional environmental indicators, identify them as a potentially useful tool to monitor environmental disruption in tropical areas. Anthropogenic disruption of the interactions between land, soil and water is widespread in tropical ecosystems and has important implications for mosquito-borne disease, particularly in light of predicted future climate change scenarios. $^{88}$ For these reasons, we have focussed the preceding discussion on mosquito-borne disease, but outbreaks of other vector borne or environmentally 
mediated diseases (e.g. schistosomiasis, leishmaniasis, Chagas disease, Lyme disease, Lassa fever, hantavirus) may also be useful indicators of disruption in tropical ecosystems.

The use of mosquito-borne disease outbreaks as an environmental monitoring tool does have some limitations however. Ecological disruption does not always result in increased mosquito-borne disease incidence, but it nevertheless remains true that disease outbreaks generally occur in disrupted rather than in natural ecosystems. Therefore mosquito-borne disease represents a specific, but not particularly sensitive bioindicator of underlying ecosystem processes related to disruption of soil-water systems, agricultural intensification, deforestation and urbanisation. Given the high cost of not detecting ecosystem disruption and letting it continue unabated, monitoring of traditional environmental indicators of ecosystem health is, wherever possible, still vitally important. We therefore suggest that a multidisciplinary solution that incorporates mosquito-borne disease data may be a synergistic and cost effective addition to existing environmental monitoring strategies in tropical settings. Such monitoring would assist in prioritising the time and place of interventions that are concurrently beneficial to both ecosystem health and human health. As with all issues in medical geology (and ecosystem health research more generally), such interventions also must continue to be multidisciplinary if they are to address the range of underlying causal factors that monitoring data represent. ${ }^{89}$

\section{References}

1. Millennium Ecosystem Assessment, Ecosystems and human wellbeing: health synthesis, Island Press, Washington DC, 2005.

2. P. Weinstein, EcoHealth, 2005, 2, 1-3.

3. N. O. Nielsen, Cad. Saúde Pública, 2001, 17 (Suppl), 69-75.

4. D. W. Macdonald and M. K. Laurenson, Biol. Conserv., 2006, 131, 143-150.

5. R. B. Finkleman, J. A. Centeno and O. Selinus, Terre, 2005, 2, 38.

6. J. E. Bunnell, EcoHealth, 2004, 1, 15-18.

7. O. Selinus, Terre, 2004, 1, 8-15.

8. O. Selinus, $A M B I O, 2007,36,114-116$.

9. G. Forget and J. Lebel, Int. J. Occup. Environ. Health, 2001, 7, S338.

10. D. Waltner-Toews, Cad. Saúde Pública, 2001, 17(Suppl), 7-36.

11. D. J. Rapport, Ecosyst. Health, 1999, 5, 174-180.

12. A. Cook, A. Jardine and P. Weinstein, Environ. Health Persp., 2004, 112, 1143-1146.

13. S. E. Jørgensen, R. Costanza and F.-L. Xu, Handbook of ecological indicators for assessment of ecosystem health, CRC Press, Taylor \& Francis Group, Boca Raton, USA, 2005.

14. J. A. Patz and U. E. C. Confalonieri, in Ecosystems and Human Well-being: Current State and Trends, Volume 1, eds. R. Hassan, R. Scholes and N. Ash, Island Press, Washington, 2005, pp. 391415.

15. D. J. Gubler, Arch. Med. Res., 2002, 33, 330-342.

16. C. C. Campbell, FEMS Immunol. Med. Microbiol., 1997, 18, 325331.

17. D. J. Gubler, Emerg. Infect. Dis., 1998, 4, 442-450.

18. N. G. Gratz, Annu. Rev. Ento., 1999, 44, 51-75.

19. D. J. Gubler, Ann. NY. Acad. Sci., 2001, 951, 13-24.

20. D. J. Gubler, Comp. Immunol. Microb. Infect. Dis., 2004, 27, 319330.
21. A. A. Marfin and D. J. Gubler, Clin. Infect. Dis., 2001, 33, 17131719.

22. J. T. Roehrig, M. Layton, P. Smith, G. L. Campbell, R. Nasci and R. S. Lanciotti, Curr. Top. Microbiol. Immunol., 2002, 267, 223240.

23. R. N. Charrel, X. de Lamballerie, D. Raoult, R. N. Charrel, X. de Lamballerie and D. Raoult, New Engl. J. Med., 2007, 356, 769771.

24. B. L. Ligon, Semin. Pediat Infect. Dis., 2006, 17, 99-104.

25. S. Higgs, Vector-Borne Zoonot. Dis., 2006, 6, 115-116.

26. C. Revenga, J. Brunner, N. Henninger, K. Kassem and R. Payne, The Pilot analysis of global ecosystems: Freshwater systems, World Resources Institute, Washington DC., 2000.

27. United Nations Educational Scientific and Cultural Organisation (UNESCO), Water for People, Water for Life - UN World Water Development Report, UNESCO Publishing / Berghahn Books, Paris, 2003.

28. World Commission on Dams, Dams and development: A new framework for decision-making. Earthscan Publications Ltd: London, 2000.

29. G. Parent, A. Ouedraogo, N. M. Zagre, I. Compaore, R. Kambire and J. N. Poda, Sante, 1997, 7, 417-422.

30. H. E. Paterson, in Man-made lakes and human health, eds. N. F. Stanley and M. P. Alpers, Academic Press Inc., London, Editon edn., 1975, pp 301-309.

31. R. C. Russell, Ecol. Eng., 1999, 12, 107-124.

32. M. S. Mulla, L. S. Mian and N. G. Gratz, J. Agric. Entomol., 1987, 97-131.

33. A. Jardine, P. Speldewinde, S. Carver and P. Weinstein, EcoHealth, 2007, 4, 10-17.

34. F. M. Kishk, H. M. Gaber and S. M. Abd-Allah, EcoHealth, 2004, 1 (Suppl. 2), 84-96.

35. W. A. Abderrahman, M. Rasheeduddin and J. K. Nejem, Int. J. Water Resour. Dev., 2000, 16, 369-390.

36. T. Temel, Acta Trop., 2004, 89, 249-259.

37. E. Klinkenberg, F. Konradsen, N. Herrel, M. Mukhtar, W. van der Hoek and F. P. Amerasinghe, Trans. R. Soc. Trop. Med. Hyg., 2004, 98, 442-449

38. M. D. A. Lindsay, A. Jardine, C. A. Johansen, A. E. Wright, S. A. Harrington and P. Weinstein, Aust. J. Ento., 2007, 46, 60-64.

39. N. Ramankutty and J. A. Foley, Global Biogeochem. Cy., 1999, 13, 997-1028.

40. P. H. Gleick, Ann. Rev. Environ. Resour., 2003, 28, 275-314.

41. D. Tilman, P. Natl. Acad. Sci. USA., 1999, 96, 5995-6000.

42. G. P. Robertson and S. M. Swinton, Front. Ecol. Environ., 2005, 3, 38-46.

43. D. Tilman, J. Fargione, B. Wolff, C. D'Antonio, A. Dobson, R. Howarth, D. Schindler, W. H. Schlesinger, D. Simberloff and D. Swackhamer, Science, 2001, 292, 281-284.

44. L. Horrigan, R. S. Lawrence and P. Walker, Environ. Health Persp., 2002, 110, 445-456.

45. J. A. Patz, P. Daszak, G. M. Tabor, A. A. Aguirre, M. Pearl, J. Epstein, N. D. Wolfe, A. M. Kilpatrick, J. Foufopoulos, D. Molyneux and D. J. Bradley, Environ. Health Persp., 2004, 112, 1092-1098.

46. M. W. Service, in Demography and vector-borne diseases, ed. M. W. Service, CRC Press, Inc., Boca Raton, Florida, 1989, pp 237254.

47. S. W. Lindsay, H. A. Wilkins, H. A. Zieler, R. J. Daly, V. Petrarca and P. Byass, J. Trop. Med. Hyg., 1991, 94, 313-324.

48. T. K. Mukiama and R. W. Mwangi, Acta Trop., 1989, 46, 181-189.

49. R. W. Mwangi and T. K. Mukiama, Hydrobiologia, 1992, 232, 1922.

50. E. Klinkenberg, W. Takken, F. Huibers and Y. T. Toure, Acta Trop., 2003, 85, 71-82.

51. E. Klinkenberg, F. Huibers, W. Takken and Y. T. Toure, Irrig. Drain. Sys., 2002, 16, 201-212.

52. A. Jardine, M. D. Lindsay, J. Heyworth and P. Weinstein, EcoHealth, 2004, 1, 387-398.

53. L. A. Lacey and C. M. Lacey, J. Am. Mos. Contr. Assoc., 1990, 2, $1-93$. 
54. J. C. Hume, E. J. Lyons and K. P. Day, Trends Parasitol., 2003, 19, 144-149.

55. J. Fayrer, Climate and fevers in India, Churchill, London, 1882.

56. R. A. Dixon and J. P. Pinikahana, Mosquito-Borne Dis. Bull., 1994, 11, 116-121.

57. M. A. Diuk-Wasser, M. B. Toure, G. Dolo, M. Bagayoko, N. Sogoba, I. Sissoko, S. F. Traore and C. E. Taylor, Am. J. Trop. Med. Hyg., 2007, 76, 869-874.

58. J. Ravindran and J. Williams, J. Parasitic Dis., 2006, 30, 45-52.

59. E. J. Muturi, J. Shililu, B. Jacob, W. Gu, J. Githure and R. Novak, J. Vector Ecol., 2006, 31, 129-137.

60. J. Keiser, M. F. Maltese, T. E. Erlanger, R. Bos, M. Tanner, B. H. Singer and J. Utzinger, Acta Trop., 2005, 95, 40-57.

61. N. Herrel, F. P. Amerasinghe, J. Ensink, M. Mukhtar, W. v. d. Hoek and F. Konradsen, Med. Vet. Entomol., 2004, 18, 141-152.

62. J. Yasuoka and R. Levins, Am. J. Trop. Med. Hyg., 2007, 76, 450460.

63. J. N. Ijumba and S. W. Lindsay, Med. Vet. Entomol, 2001, 15, 111.

64. J. N. Ijumba, F. C. Shenton, S. E. Clarke, F. W. Mosha and S. W. Lindsay, Trans. R. Soc. Trop. Med. Hyg., 2002, 96, 476-480.

65. R. De Plaen, R. Geneau, T. Teuscher, A. Koutoua and M. L. Seka, Trop. Med. Int. Health, 2003, 8, 459-470.

66. F. Achard, H. D. Eva, H.-J. Stibig, P. Mayaux, J. Gallego, T. Richards and J.-P. Malingreau, Science, 2002, 297, 999.

67. F. B. Livingston, Am. Anthropol., 1958, 60, 533-562.

68. S. Munga, N. Minakawa, G. Zhou, E. Mushinzimana, O.-O. J. Barrack, A. K. Githeko and G. Yan, Am. J. Trop. Med. Hyg., 2006, 74, 69-75.

69. N. Tuno, W. Okeka, N. Minakawa, M. Takagi and G. Yan, J. Med. Entomol., 2005, 42, 270-277.

70. K. A. Lindblade, E. D. Walker, A. W. Onapa, J. Katungu and M. L. Wilson, Trop. Med. Int. Health, 2000, 5, 263-274.

71. Y. A. Afrane, B. W. Lawson, A. K. Githeko and G. Y. Yan, J Med. Entomol., 2005, 42, 974-980.

72. W. Tadei, B. Thatcher, J. Santos, V. Scarpassa, I. Rodrigues and M. Rafael, Am. J. Trop. Med. Hyg., 1998, 59, 325-335.

73. B. H. Singer and M. C. De Castro, Ann. NY Acad. Sci., 2001, 954, 184-222.

74. A. Y. Vittor, R. H. Gilman, J. Tielsch, G. Glass, T. Shields, W. S. Lozano, V. Pinedo-Cancino and J. A. Patz, Am. J. Trop. Med. Hyg., 2006, 74, 3-11.

75. P. F. Vasconcelos, A. P. Travassos da Rosa, S. G. Rodrigues, E. S. Travassos da Rosa, N. Degallier and J. F. Travassos da Rosa, Cad. Saúde Pública, 2001, 17 Suppl, 155-164.

76. B. L. Montgomery, S. A. Ritchie, A. J. Hart, S. A. Long and I. D. Walsh, J. Am. Mosq. Contr. Assoc., 2004, 20, 365-369.

77. B. M. Russell, W. J. McBride, H. Mullner, B. H. Kay and W. J. J. McBride, J. Med. Entomol, 2002, 39, 143-145.

78. B. H. Kay, P. A. Ryan, B. M. Russell, J. S. Holt, S. A. Lyons and P. N. Foley, J. Med. Entomol., 2000, 37, 846-853.

79. T. Su, J. P. Webb, R. P. Meyer and M. S. Mulla, J. Vector Ecol., 2003, 28, 79-89.

80. J. Cox, M. E. Grillet, O. M. Ramos, M. Amador and R. Barrera, Am. J. Trop. Med. Hyg., 2007, 76, 820-826.

81. World Health Organisation, Dengue haemorrhagic fever: diagnosis, treatment, prevention and control. 2nd edition. WHO: Geneva, 1997.

82. D. J. Gubler, Trends Microbiol., 2002, 10, 100-103.

83. D. J. Gubler and M. Meltzer, Adv. Virus Res., 1999, 53, 35-70.

84. V. Robert, K. Macintyre, J. Keating, J. F. Trape, J. B. Duchemin, M. Warren and J. C. Beier, Am. J. Trop. Med. Hyg., 2003, 68, 169-176.

85. J. Hamon and G. Dufour, Bull. Org. Mond. Santé., 1954, 11, 525556.

86. J. Julvez, C. Ragavoodoo, A. R. Gopaul and J. Mouchet, Bull. Soc. Pathol. Exot., 1998, 91, 99-103.

87. M. Gonçalves and W. Alecrim, Rev. Sauld Pública, 2004, 6, 156166.

88. J. A. Patz and S. H. Olson, Ann. Trop. Med. Parasitol., 2006, 100, 535-549.
89. R. B. Finkelman, J. A. Centeno and O. Selinus, Trans. Am. Clin. Climatol. Assoc., 2005, 116, 155-165. 